\title{
3D FE- SIMULATION OF THERMALLY ASSISTED TURNING OF INCONEL-718 FOR CUTTING FORCES PREDICTION
}

\author{
Adel K.Mahmoud and Khalaf Nasralla \\ Department of Mechanical Department, college of Engineering, \\ University of Diyala, Iraq \\ Suha K. Shihab \\ Department of Materials Engineering, college of Engineering, \\ University of Diyala, Iraq
}

\begin{abstract}
This paper investigates the effect thermally assisted turning (TAT) of different cutting parameters (cutting speed, feed rate, and depth of cut) on cutting force under dry hard turning process of Inconel 718. 3D FE simulations based ABAQUS/explicit of both orthogonal and oblique turning processes were performed. the results indicated that 3D FE modeling provides the reliability to predict cutting forces during turning process by validation the obtained results with the experimental results. Also, the results indicated that $3 D$ models of oblique machining have more accurate results as compare with orthogonal models although computing time is larger for $3 D$ oblique machining models. In addition, the results show that the cutting force decreases significantly with increase cutting speed and workpiece temperature while it increases with increase the feed rate and depth of cut.
\end{abstract}

Keywords: Thermally assisted turning, Inconel 718; Cutting forces; 3D-FE Simulation.

Cite This Article: Adel K. Mahmoud, Khalaf Nasralla and Suha K. Shihab, 3D FESimulation of Thermally Assisted Turning of Inconel-718 for Cutting Forces Prediction, International Journal of Design and Manufacturing Technology (IJDMT), 9(2), 2018, Pp 23-34

https://iaeme.com/Home/issue/IJDMT?Volume $=9 \&$ Issue $=2$ 


\title{
NOMENCLATURE
}

\author{
$\sigma=$ Flow stress \\ $\mathrm{A}=$ Yield stress constant \\ $\mathrm{B}=$ Strain hardening coefficient \\ $\varepsilon=$ Equivalent plastic strain \\ $\varepsilon^{\circ}=$ Strain rate \\ $\mathrm{n}=$ Strain hardening exponent \\ $\varepsilon^{\circ} 0=$ Reference strain rate \\ $\mathrm{C}=$ Strain rate dependence coefficient $\mathrm{T}$ room $=$ Room temperature \\ $\mathrm{Tm}=$ Melting temperature \\ $\mathrm{m}=$ Temperature dependence coefficient
}

\section{INTRODUCTION}

Nickel-based superalloys are generally utilized in hostile environments such as gas turbines and jet engines because of their high corrosion and oxidation resistance, superior thermal fatigue resistance and fracture toughness. Inconel 718 is one of the nickel based superalloy which it was used in automobile, aerospace, and marine applications due to its high strength to weight ratio, mechanical and thermal properties. In addition, Inconel 718 alloy is an austenitic nickelbase superalloy which is utilized in the functions that require high strength to approximately $1400^{\circ} \mathrm{F}\left(760^{\circ} \mathrm{C}\right)$ with oxidation resistance to about $1800^{\circ} \mathrm{F}\left(982^{\circ} \mathrm{C}\right)$. However, Super alloys like alloys of nickel, nickel iron and cobalt have poor machinability and their characteristics that provide superior high-temperature strength make them difficult to machine $[1,2 \cdot 3,4,5,6]$.

The heat generation during machining process has direct influence on the cutting force, tool wear and quality of the machined surface. The knowledge about the relation between the cutting force and cutting parameters like tool geometry, workpiece material, feed rate, depth of cut, cutting speed etc. assists the designer and the manufacturer for raising the efficiency of machine tools $[7,8]$. Therefore, many studies have been made to understand the relation between cutting parameter and cutting force. D.K. Aspinwall et al. [9] studied the effects of variables i.e. cutter orientation and workpiece tilt angle on the cutting force during high speed milling of Inconel 718under finishing conditions. The results revealed that the cutting force was highest with the 01 workpiece tilt angle. Tool chatter was evident with the horizontal upwards cutter orientation which cause the fluctuations in the cutting force signatures. A Mehta et al. [10] investigated the influence of different sustainable machining environments such as dry, minimum quantity lubrication (MQL), cold air and cryogenic on the cutting force. The results showed that machining using combination of cold air and MQL tends to reduce the cutting force by about $28 \%$ when compared to dry machining. Sana J. Yaseen [11] studied the effect of different rake angles, feed rates, work piece material on cutting force during turning process using a finite element analysis. Yash R. Bhoyar and Kamble [12] built a finite element analysis simulation model of orthogonal machining in order to obtain the cutting forces occurring at different points through the chip/tool contact region and the coating/substrate boundary for a range of cutting tool materials. AISI 1040 carbon steel (mild steel), is modeled as the workpiece with thermo elastic plastic material. Their result indicated that the cutting force has been found to be an important variable in the generation of surface temperature and increase the value of rake angle in positive section caused the decrease of the cutting force. On the other hand, increasing the rake angle in negative section increases the cutting force. S Sulaiman et al. [13] constructed a Finite Element Method (FEM) based on the ABAQUS/explicit software to simulate cutting force during high speed machining (HSM) of AISI 4340 steel. They observed that cutting forces trend to decrease as rake angle increased to positive direction. C. J. Rao et al. [14] presented a study about the influence of speed, feed and depth of cut on cutting force during machining AISI 1050 steel with tool made of ceramic (A12O3+TiC matrix). Taguchi method was used in 
this study for analysis these effects. Their result illustrated that depth of cut has a significant influence on cutting force at selected cutting tool. Renjith V B et al [15] searched a deflection of cutting tool during machining of grades of steel and its effect on the forces. Their results showed that all the components of cutting force slightly decrease with tool extension length. Ved Prakash Singh Parihar et al. [16] found that cutting forces have significant impact on cutting process stability. They used ABAQUS/ explicit based on FEM for the chip formation with machining of AISI 4140 steel. Their results reveled that all the cutting parameters have effect on the measured cutting forces, but the effect of feed and depth of cut is more than spindle speed. Zaid S. Hammoudi and Iman M. Naemah [17] applied FEM simulation of orthogonal turning process using MSC Marc 2013to study the effects of feed rate and rack angle of cutting tool on cutting force. Their analyses demonstrated that cutting forces increase with the increase of cutting feed, and decrease with the increase of rack angle of cutting tool. Ye Li and Chunbin Cai [18] investigated the effect of tool rake angle, back angle, cutting speed and feed rate on cutting force in machining of nickel-based superalloy GH4169 using PCBN tool. They established two-dimensional cutting simulation model using ABAQUS software. Their result concluded that the increase of the feed rate caused increase in the cutting force linearly. Also, the cutting speed reduce the cutting force slightly. Shihab S.K. et al. [19] investigated the effect of different cutting parameters (cutting speed, feed rate, and depth of cut) on the cutting forces during turning of AISI 52100 alloy steel using coated carbide tool. Their results indicated that cutting forces principally are influenced by the depth of cut, while the effect of both cutting speed and feed rate is small. Changfeng Yao et al. [20] studied vary cutting force during turning of alloy Inconel718 using carbide tools and ceramic tools. Their result showed that the cutting force has main positive relative to both the feed rate and depth of cut while the cutting speed exerted the least influential effect. G Venkatesh and D Chakradhar [21] described experimentally the effect of thermally assisted machining (TAM) parameters on the cutting force of Inconel718. Their result referred that cutting force decreases with increases in cutting speed and workpiece temperature while it increases with increase feed rate and depth of cut. Taec et al. [22 ] investigated the effect of tool materials (HM and CBN) on the cutting forces during turning EN 90MnCrV8 hardened steel. Their result showed that the values of cutting force is lower when turning using $\mathrm{HM}$ as compare to $\mathrm{CBN}$ tool.

The aim of this research is investigating the effect of thermally assisted turning (TAT) parameters i.e. (cutting speed, feed rate, and depth of cut) on cutting force under dry hard turning process of Inconel 718 using 3D FE simulations based ABAQUS/explicit for both orthogonal and oblique turning processes. Also the validation of experimental results of previous study with obtained simulation data was achieved [21].

\section{NUMERICAL MODELING}

The numerical modeling was carried out using 3D finite element method (FEM). Finite element simulation of turning process was design using ABAQUS explicit with an Arbitrary Lagrangian-Eulerian (ALE) formulation method. This characteristic is essential in simulation of such complex process which includes separation and chip formation from original workpiece. Further, ABAQUS (Dynamic explicit) can deal with complex material models such as strain hardening dependent plastic properties and temperature dependent mechanical properties.

\subsection{Workpiece Modeling}

The workpiece material was modeled as plastic Inconel 718 material. The chemical composition of this material is presented in table 1 relying on experimental study of the previous study [21]. In addition, table 2 shows the mechanical Properties of 1 nconel718 alloys at room 
3D FE- Simulation of Thermally Assisted Turning of Inconel-718 for Cutting Forces Prediction

temperature [6]. Also, the physical and thermal properties of Inconel 718 are presented in table 3 .

Table 1 chemical composition of 1 nconel718 alloys [21]

\begin{tabular}{|c|c|c|c|c|c|c|c|}
\hline Element & $\mathbf{C}$ & $\mathbf{T i}$ & $\mathbf{C r}$ & $\mathbf{F e}$ & $\mathbf{N i}$ & $\mathbf{N b}$ & $\mathbf{M o}$ \\
\hline Percentage & 8.24 & 0.59 & 14.81 & 15.46 & 54.39 & 4.10 & 2.41 \\
\hline
\end{tabular}

Table 2 Mechanical Properties of 1nconel718 alloys at room temperature [5].

\begin{tabular}{|c|c|c|c|c|}
\hline Alloy & $\begin{array}{c}\text { Yield } \\
\text { strength } \\
(\mathbf{M P a})\end{array}$ & $\begin{array}{c}\text { Ultimate tensile } \\
\text { stress } \\
(\mathbf{M P a})\end{array}$ & $\begin{array}{c}\text { Elongation } \\
(\boldsymbol{\%})\end{array}$ & $\begin{array}{c}\text { Young } \\
\text { modulus } \\
(\mathbf{G P a})\end{array}$ \\
\hline Inconel 718 & 1100 & 1375 & 25 & 200 \\
\hline
\end{tabular}

Table 3 Physical and Thermal Properties of Inconel 718 [23,24,25]

\begin{tabular}{|c|c|}
\hline Property & Temp. 21 $^{\circ} \mathbf{C}$ \\
\hline Yield strength $(\mathrm{MPa})$ & 1310 \\
\hline Elastic modulus $(\mathrm{GPa})$ & 206 \\
\hline $\begin{array}{c}\text { Specific heat capacity }\left(\mathrm{J} / \mathrm{Kg} .{ }^{\circ} \mathrm{C}\right) \\
\text { Thermal conductivity }\left(\mathrm{W} / \mathrm{m} .{ }^{\circ} \mathrm{C}\right)\end{array}$ & 430 \\
\hline $\begin{array}{c}\text { Coefficient of thermal expansion }(10-6 \\
\left./{ }^{\circ} \mathrm{C}\right)\end{array}$ & 11.2 \\
\hline Melting range $\left({ }^{\circ} \mathrm{C}\right)$ & $1260-1335$ \\
\hline Density $(\mathrm{Kg} / \mathrm{m} 3)$ & 8470 \\
\hline
\end{tabular}

The workpiece was created with dimensions at $35 \mathrm{~mm}$ diameters with long at $20 \mathrm{~mm}$. Workpiece was then meshed with element type C3D8RT have 8 node hexahedron temperature displacement coupled with reduced integration and hourglass control which are suitable for explicit dynamics analyses to reduce the running time and chip formation. ALE adaptive meshing combined with pure Langrangian boundary condition are implemented to mesh the workpiece. The number of mesh of the workpiece in the 3D oblique machining was (58300) elements with approximate global size $(0.02 \mu \mathrm{m})$. While the number of mesh of the workpiece in the $3 \mathrm{D}$ orthogonal machining was (3500) elements with approximate global size $(0.02 \mu \mathrm{m})$. Element number has been changed in every model due to using deference in the values of depth and feed. Disruption of the finite element mesh is necessary for modelling chip formation, therefore besides the material model, the Johnson-Cook damage model was also applied. This is a fracture model for ductile materials and consists of two phases, a damage initiation and a damage evolution phase. The Johnson-Cook damage model assumes that the equivalent strain at failure is given in the eq 1 :

$$
\sigma=\left[A+B \varepsilon^{n}\right]\left[1+c \quad L n \cdot \frac{\varepsilon^{\circ}}{\varepsilon^{\circ}}\right]\left[1-\left(\frac{T-T^{\circ}}{T m-T^{\circ}}\right) m\right.
$$

Table 4 Johnson-Cook material model constants for Inconel 718 [23,24,25]

\begin{tabular}{|c|c|c|c|c|c|c|}
\hline $\begin{array}{c}\mathbf{A} \\
(\mathbf{M P a})\end{array}$ & $\begin{array}{c}\mathbf{B} \\
(\mathbf{M P a})\end{array}$ & $\mathbf{c}$ & $\mathbf{n}$ & $\mathbf{m}$ & $\mathbf{T}$ room $\left({ }^{\circ} \mathbf{C}\right)$ & $\mathbf{T}_{\mathbf{m}}\left({ }^{\circ} \mathbf{C}\right)$ \\
\hline 1241 & 622 & 0.017 & 0.65 & 1.3 & 20 & 1297 \\
\hline
\end{tabular}




\subsection{Tool Modelling}

The tool geometry has a great influence on the cutting force and temperature generated on the machined workpiece, so it has been given a very keen importance for the design tool geometry during the modelling of machining process. In this study, PVD carbide insert material with ISO designation (SNMG120408) was used in the simulation. The cutting insert was assumed to be a rigid body with reference point. Geometric variables of the insert are given in table 5 and depending on the earlier studies from literature [21]. Mechanical and thermal properties of carbide insert are given in table 6.

The element type that used in both orthogonal and oblique modeling was CED8R have 8 nodes and it is a linear brick element with Tet-element shape. The number of elements for the tool during oblique modeling is approximate 580 and global size $(0.8 \mathrm{~mm})$ while the number of elements for the tool during orthogonal modeling is 28 element. The mesh density on the radius of the insert was high to make the curve smoother and to increase the accuracy of the result in this zone. Figure1. ( $a$ and $b$ ) shows 3D. finite element mesh models for both orthogonal and oblique machining.

Table 5 Geometric variables of the insert

\begin{tabular}{|c|c|}
\hline Tool Type & SNMG120408 \\
\hline Rake Angle, $\boldsymbol{\alpha}$ & -6 \\
\hline Noise radius $(\mathbf{m m})$ & 0.8 \\
\hline
\end{tabular}

Table 6 Mechanical and thermal properties of Cutting insert [23,24,25]

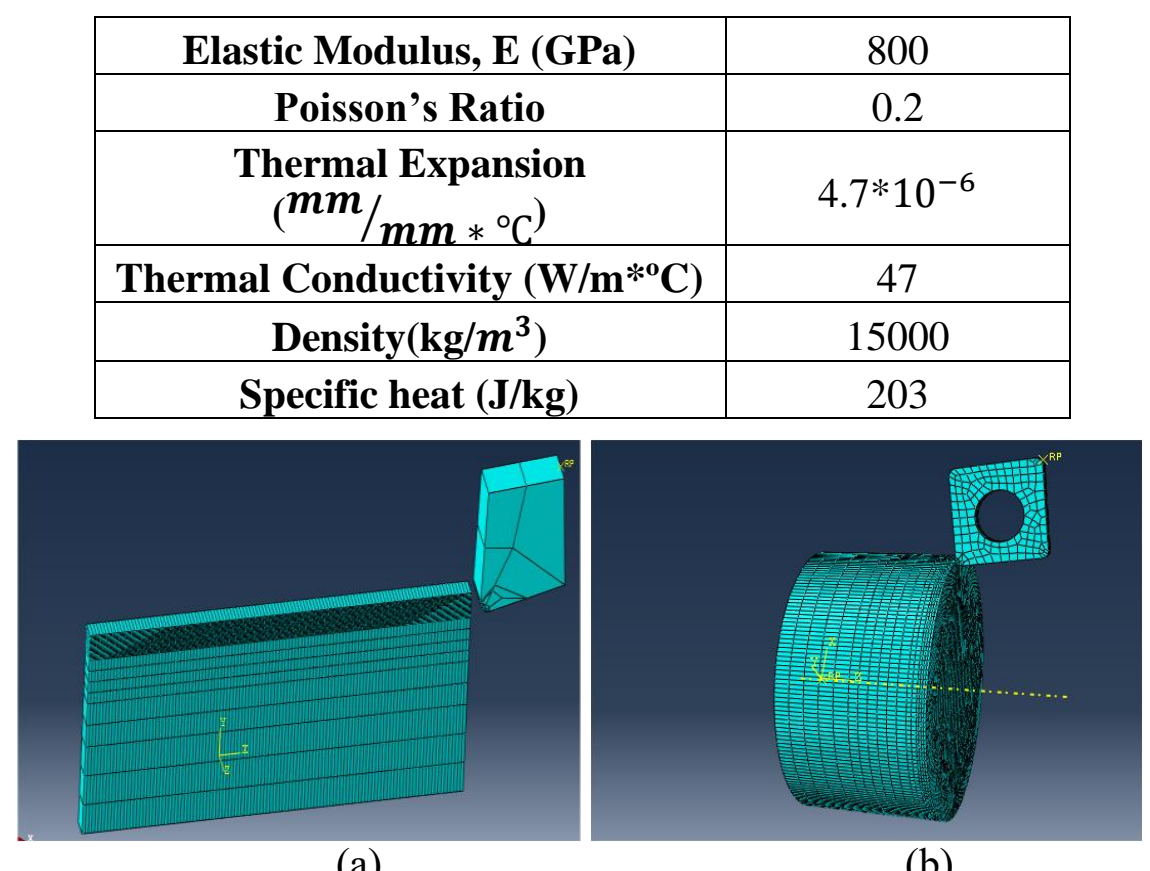

(a)

(b)

Figure 1 Finite element mesh model of cutting simulation (a) orthogonal machining, (b) oblique machining

\section{CUTTING PARAMETERS}

Four cutting parameters i.e. (cutting speed, depth of cut, feed rate and cutting temperature) with five levels for each parameter were used in the modeling. table 7 represents different cutting parameters with their levels. These values are selected based on experimental work of the 
previous study from literature [21]. Friction coefficient between cutting tool and workpiece/chip is taken as ( $\mu=0.3$ Coulomb friction combined). Twenty models have been constructed according to the levels of parameters.

Table 7 Turning process parameters and their levels

\begin{tabular}{|c|c|c|c|c|c|c|c|}
\hline Symbol & Machining & units & Level 1 & Level 2 & Level & Level & Level 5 \\
\hline A & Cutting speed & $(\mathrm{m} / \mathrm{min})$ & 18 & 34 & 52 & 72 & 90 \\
\hline B & Feed rate & $(\mathrm{mm} / \mathrm{rev})$ & 0.048 & 0.071 & 0.096 & 0.119 & 0.143 \\
\hline C & Depth of cut & $(\mathrm{mm})$ & 0.2 & 0.3 & 0.4 & 0.5 & 0.6 \\
\hline D & Workpiece temperature & $\left({ }^{\circ} \mathrm{C}\right)$ & 200 & 300 & 400 & 500 & 600 \\
\hline
\end{tabular}

\section{BOUNDARY CONDITION}

In $3 \mathrm{D}$ oblique simulation, the workpiece material was free in $\mathrm{z}$-axis i.e. in the direction of angular velocity while tool material was allowed movement in the $\mathrm{z}$ - axis i.e. in the feed direction as shown on Fig.2 (b). In 3D orthogonal simulation, the workpiece was constrained with boundaries on bottom and both sides of the workpiece and the tool was constrained to move only along x-direction as shown in Fig.2 (a). Pre heating temperature i.e. (TAT) was applied at the top surface of the workpiece using temperature boundary conditions at $\left(200,300,400,500,600^{\circ} \mathrm{C}\right)$.

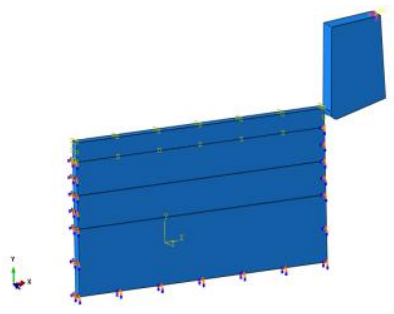

(a)

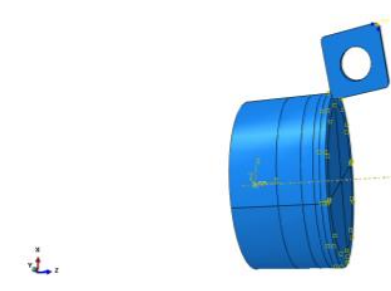

(b)

Figure 2 (a) Boundary conditions used in 3D simulation: a) orthogonal machining b) oblique machining

\section{RESULTS AND DISCUSSIONS}

In this section, the predicted values of cutting force that obtained from the $3 \mathrm{D}$ orthogonal machining, 3D oblique machining and experimental models have been discussed and validated with the experimental results. Fig. 3 ( $a$ and $b$ ) shows the simulation results of orthogonal machining and oblique machining simultinouslty.

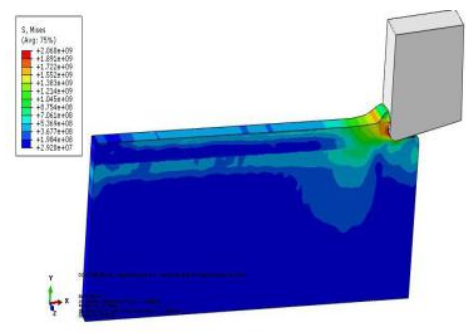

(a)

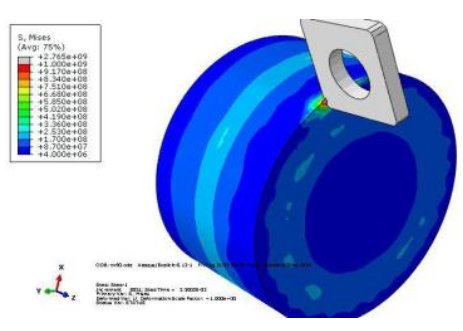

(b)

Figure 3 Simulation results a) orthogonal machining, b) oblique machining 


\subsection{Effect of Cutting Speed}

In order to study the effect of cutting speed on the cutting force, five levels of cutting speed were taken $(18,32,52,72,90 \mathrm{~m} / \mathrm{min})$ at constant values of other parameters means (depth of cut $=0.6 \mathrm{~mm}$, feed rate $=0.048 \mathrm{~mm} / \mathrm{rev}$ and $\mathrm{T}=600{ }^{\circ} \mathrm{C}$ ). table 8 shows predicted values of cutting force that obtained from 3D orthogonal machining model, 3D oblique machining model, and experimental work with difference of cutting speed values. It can be observed from table 8 that the readings of cutting force of oblique model closer to the experimental readings as compare to orthogonal machining model. Figure 4. reveals to the effect of cutting speed on cutting forces that obtained from the orthogonal model, oblique model and the experimental machining. It can be confirmed from the Figure that the oblique model is more suitable and accurate for validation and verification of experimental results than orthogonal model in simulation the machining process. These results show that the cutting forces decrease with increase cutting speed because material removal becomes softer and easy with more heat generation at higher speeds which essential to raise shear plane energy.

Table 8 Predicted cutting force with variation of cutting speeds

\begin{tabular}{|c|c|c|c|c|}
\hline No Exp. & $\mathbf{v}(\mathbf{m} / \mathbf{m i n})$ & 3D orthogonal F(N) & 3D oblique $\mathbf{F}(\mathbf{N})$ & Exp. F(N) \\
\hline 1 & 18 & 287 & 311 & 335 \\
\hline 2 & 34 & 165 & 207 & 225 \\
\hline 3 & 52 & 154 & 179 & 200 \\
\hline 4 & 72 & 149 & 166 & 185 \\
\hline 5 & 90 & 121 & 141 & 170 \\
\hline
\end{tabular}

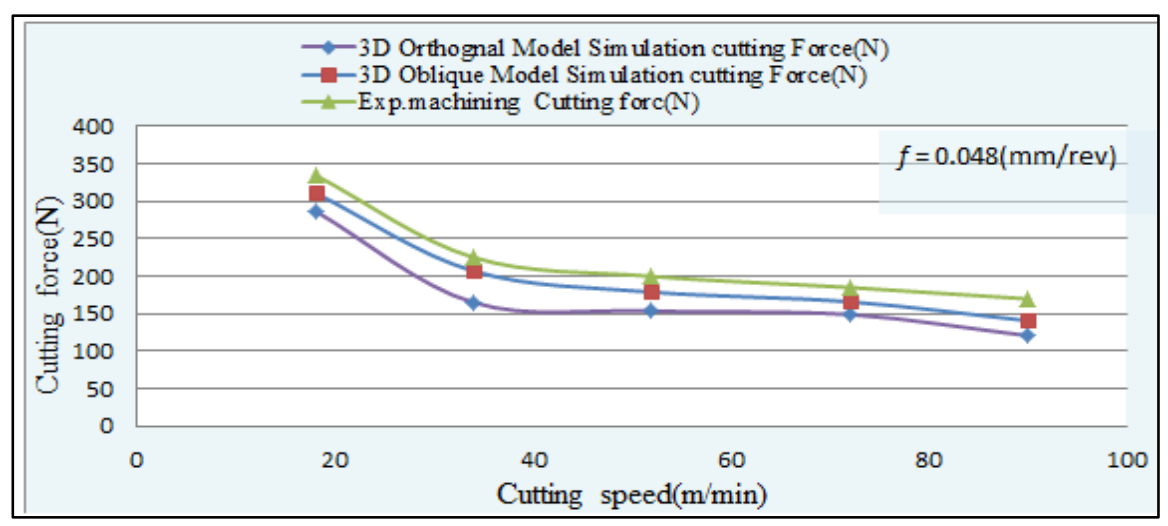

Figure 4 Effect of cutting speed with TAT on the cutting force.

\subsection{Effect of Feed Rate}

To study the effect of feed rate on the cutting force, five levels of cutting speed were taken $(0.048,0.071,0.096,0.119,0.143 \mathrm{~mm} / \mathrm{rev})$ at constant values of other parameters means (depth of cut $=0.6 \mathrm{~mm}$, cutting speed $=90 \mathrm{~m} / \mathrm{min}$, and $\mathrm{T}=600^{\circ} \mathrm{C}$ ). table 9 illustrates predicted values of cutting force that obtained from 3D orthogonal machining model, 3D oblique machining model and experimental work models at different values of feed rate. It can be observed from table 9 that the values of cutting force of oblique model closer to the experimental values as compare to orthogonal machining model. Figure 5. exposes the effect of feed rate on cutting forces that obtained from the orthogonal model, oblique model and the experimental machining. The results demonstrate that the larger value for cutting force was obtained at higher value of the feed rate and the cutting force increases significantly with increase feed rate value due to 
3D FE- Simulation of Thermally Assisted Turning of Inconel-718 for Cutting Forces Prediction

increasing the material removal rate and increasing the contact area between the chip and tool which resulted in increase the value of friction during turning process.

Table 9 Predicted cutting force with variation of feed rates

\begin{tabular}{|c|c|c|c|c|}
\hline No Exp. & $\boldsymbol{F}(\mathbf{m m})$ & 3D orthogonal $\mathbf{F}(\mathbf{N})$ & 3D oblique $\mathbf{F}(\mathbf{N})$ & Exp. F(N) \\
\hline 1 & 0.048 & 111 & 125 & 182 \\
\hline 2 & 0.071 & 182 & 207 & 225 \\
\hline 3 & 0.096 & 209 & 228 & 250 \\
\hline 4 & 0.119 & 260 & 278 & 300 \\
\hline 5 & 0.143 & 311 & 331 & 370 \\
\hline
\end{tabular}

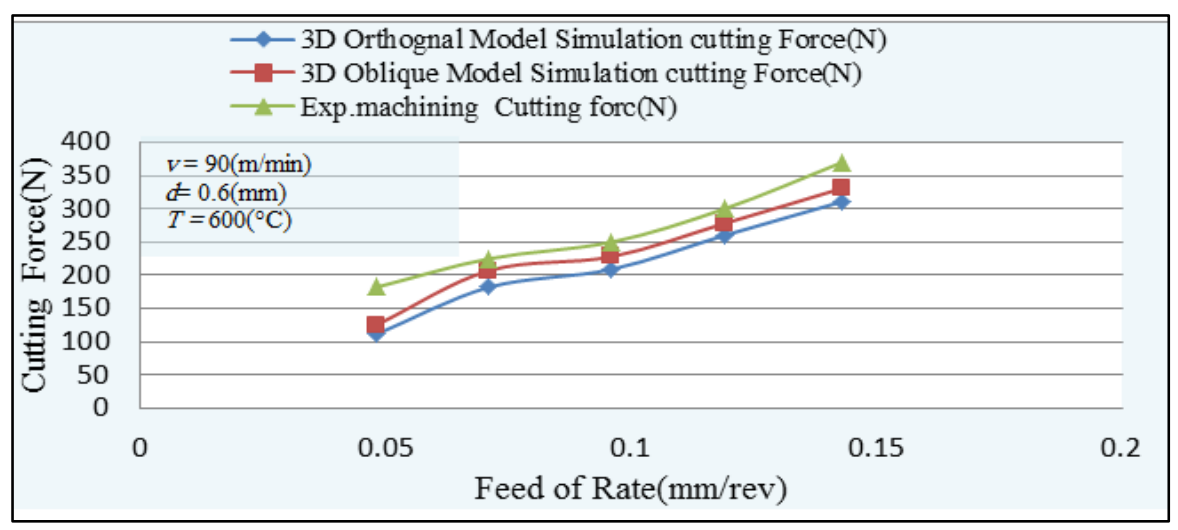

Figure 5 Effect of feed rate with TAT on the cutting force.

\subsection{Effect of Depth of Cut}

Investigation the effect of depth of cut on the cutting force was obtained using five levels of depth of cut $(0.048,0.071,0.096,0.119,0.143 \mathrm{~mm} / \mathrm{rev})$ at constant values of other parameters i.e. $\left(\right.$ feed rate $=0.048 \mathrm{~mm} / \mathrm{rev}$, cutting speed $=90 \mathrm{~m} / \mathrm{min}$, and $\mathrm{T}=600{ }^{\circ} \mathrm{C}$ ). table 10 demonstrates predicted values of cutting force that obtained from FE model of orthogonal machining, 3D FE model of oblique machining and experimental work with variation of depth of cut. It can be also proved from table 10 that the oblique model is closer to the experimental values as compare to orthogonal machining model. Figure 6 . shows the effect of depth of cut on the cutting force. It can be observed from the Figure that cutting force increases with increase depth of cut and these due to the chip formation and increasing contact area between the chip and tool edge which leads to increase the value of friction during turning process.

Table10 Predicted cutting force with variation of depth of cut

\begin{tabular}{|c|c|c|c|c|}
\hline No Exp. & d (mm) & 3D orthogonal F(N) & 3D oblique F(N) & Exp. F(N) \\
\hline 1 & 0.2 & 111 & 125 & 150 \\
\hline 2 & 0.3 & 189 & 219 & 245 \\
\hline 3 & 0.4 & 189 & 228 & 255 \\
\hline 4 & 0.5 & 260 & 278 & 300 \\
\hline 5 & 0.6 & 318 & 331 & 350 \\
\hline
\end{tabular}


Adel K. Mahmoud, Khalaf Nasralla and Suha K. Shihab

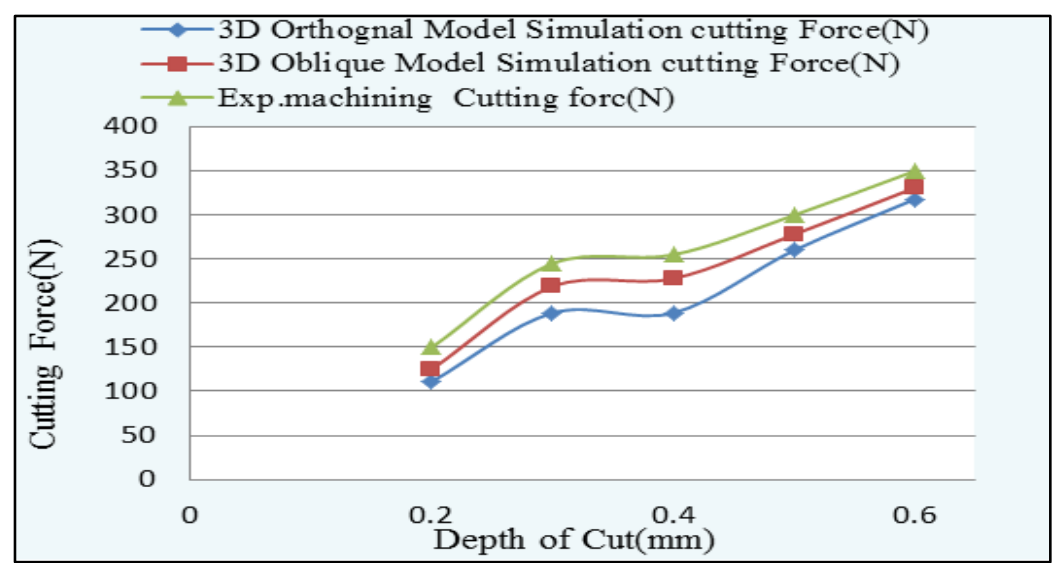

Figure 6 Effect of depth of cut with TAT on the cutting force.

\subsection{Effect of Temperature}

five values of workpiece temperature $\left(200,300,400,500,600^{\circ} \mathrm{C}\right)$ have been considered to study the effect of temperature on the cutting force with constant values of other parameters i.e. (feed rate $=0.048 \mathrm{~mm} / \mathrm{rev}$, cutting speed $=90 \mathrm{~m} / \mathrm{min}$, and depth of cut $=0.6 \mathrm{~mm}$ ). table 11 displays predicted values of cutting force that obtained from 3D FE model of orthogonal machining, 3D FE model of oblique machining and experimental work with variation of workpiece temperature. It can be also observed from table 11 that the values of cutting force of oblique model closer to the experimental values as compare to orthogonal machining model. Figure 7. reveals to the effect of temperature on the cutting force during turning with different values of temperature. It can be noticed that cutting force decreases with increase temperature. These result because the decrease of yield strength of the machining workpiece results in decrease in the generation of cutting force.

Table 11 Predicted cutting force with variation of cutting temperature

\begin{tabular}{|c|c|c|c|c|}
\hline No Exp. & T $\left({ }^{\mathbf{o}} \mathbf{C}\right)$ & 3D orthogonal F(N) & 3D oblique $\mathbf{F}(\mathbf{N})$ & Exp. F(N) \\
\hline 1 & 200 & 222 & 258 & 270 \\
\hline 2 & 300 & 165 & 182 & 230 \\
\hline 3 & 400 & 133 & 166 & 220 \\
\hline 4 & 500 & 119 & 143 & 190 \\
\hline 5 & 600 & 125 & 156 & 183 \\
\hline
\end{tabular}

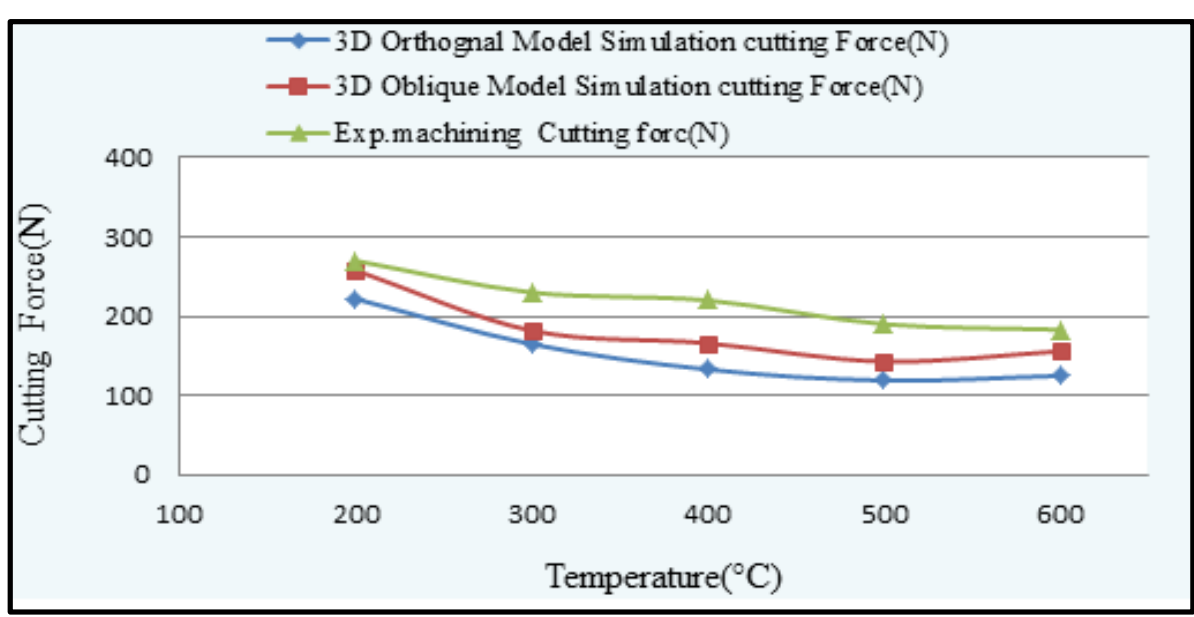

Figure 7 Effect of temperature on the cutting force. 


\section{CONCLUSIONS}

This study aims to investigate the effect of different thermally assisted turning (TAT) parameters (cutting speed, feed rate, and depth of cut) on the cutting forces using 3D FE simulation based ABAQUS/explicit. 3D FE simulations of both orthogonal and oblique turning process of Inconel 718 material were carried out. On the base of obtained results it can be concluded the following:

1) FEM based ABAQUSE simulation of turning process with using Johnson cook flow stress model can reliably simulate and predict cutting forces during turning process and gives a good agreement with the experimental results.

2) The 3D FE simulation of oblique machining is robustly oriented on the optimization of turning of difficult-to-machine materials such Inconel 718 and its results more accurate than 3D FE model of orthogonal machining which it provides closer results to the experimental results.

3) It was found from the simulation that the using thermally assisted turning (TAT) method to elevate the workpiece temperature improves the machinability and facilitate the process of material removal.

4) It was observed that during thermally assisted turning (TAT), the cutting force decrease with increase the cutting speed and workpiece temperature.

5) The cutting force increase with increase of feed rate and depth of cut during thermally assisted turning (TAT).

\section{REFERENCES.}

[1] Yujie Chen .PREDICTION OF SUBSURFACE DAMAGE DURING MACHINING NICKELBASEDSUPERLLOYS, unpublished Doctor of Philosophy Thesis Submitted to, (2013) ,pp. 125, Clemson University, USA.

[2] Zhiyang Huang, shajioe He, Zhuang Kejia, Xiaoming Zhang, Han Ding (An analysis of cutting Parameter, Coated materials and nose radii on residual stresses when turning Inconel 718) Procedia CIRP 46 ( 2016 )pp. 368-371.

[3] VDM metal Alloy 718 (Material Data Sheet No. 4127) (2016) pp.1-7, Nicrofer 5219 Nb (3).

[4] Samuel J. Rosenberg (Nickel and Its Alloys) Institute for Materials Research National Bureau of Standards, Washington, (1968). pp.1-25, D.C. 20234.

[5] Enes Akca and Ali Gursel, A Review on Superalloys and IN718 Nickel Based INCONEL Super alloy, Periodicals of Engineering and Natural Sciences, vol.3. no.1 (2015) ISSN 2303-4521. http://dx.doi.org/10.21533/pen.v3i1.43

[6] Monika Losertova (Advanced Materials) 1st, textbook, (2014) pp.8-30, Technical University of Ostrava.

[7] Ma, Yaowei Yong,and, Shuting Lei (3D FEM Investigation of the Effects of Nose Radius and Edge Radius on Turning of AISI 4140. Proceedings of the ASME 2012 International Mechanical Engineering Congress \& Exposition.

[8] S Sulaiman, A Roshana, and M K A Ariffin, Finite Element Modeling of the effect of tool rake angle on tool temperature and cutting force during high speed machining of AISI 4340 steel. (2013) IOP Conf. Series: Materials Science and Engineering 50. 
[9] D.K. Aspinwalla, R.C. Dewesa, E.-G. Ngb, C. Sagec, S.L. Soo (The influence of cutter orientation and workpiece angle on machinability when high-speed milling Inconel 718 under finishing conditions) International Journal of Machine Tools \& Manufacture 47 (2007) pp.1839-1846.

[10] A Mehta, S.Hemakumar, A.Patil, S.P.Khandke, P.Kuppan, R.Oyyaravelu, A.S.S.Balan, Infrluence of sustainable cutting environments on cutting forces, surface roughness and tool wea in turning of Inconel 718. Materials Today: Proceedings 5 - (2018)pp.6746-6754.

[11] Sana J. Yaseen, THEORETICAL STUDY OF TEMPERATURE DISTRIBUTIONAND HEAT FLUX VARIATION IN TURNING PROCESS. Al-Qadisiya Journal for Engineering Sciences, Vol. 5, No. 3, (2012) pp. 299-313.

[12] [Yash R. Bhoyar1, Prof. P. D. Kamble, Finite Element Analysis on Temperature Distribution of Turning Process. International Journal of Modern Engineering Research (IJMER) www.ijmer.com Vol.3, Issue.1, (2013) pp-541-546 ISSN: 2249-6645.

[13] S Sulaiman, A Roshana, M K A Ariffin, Finite Element Modeling of the effect of tool rake angle on tool temperature and cutting force during high speed machining of AISI 4340 steel. OP Conf. Series: Materials Science and Engineering 50 - (2013)012040.

[14] C. J. Rao, Dr. D. Nageswara Rao, P. Sriharic, Influence of cutting parameters on cutting force and surface finish in turning operation. Procedia Engineering 64 - (2013) pp.1405 - 1415.

[15] Renjith V B, Mathew Baby, K R Jayadevan (Influence of process parameters on cutting forces and Taguchi based prediction of T42 - CT H.S.S single point cutting tool deflection) International Journal of Scientific and Research Publications, Volume 3, (2013) Issue 7.

[16] Ved Prakash Singh Parihar, M. A. Saloda, B.P. Nandwana and M. S. Khidiya (Effects of Cutting Parameters on Cutting Forces: An Experimental Study and Numerical Modeling of Turning Operation by Finite Element Analysis) An International Peer Review E-3 Journal of Sciences and Technology. JECET; Sec. C; Vol.4. No.4, (2015) pp.532-544.

[17] Zaid S. Hammoudi, Iman M. Naemah (EFFECT OF FEED RATEAND RACK ANGLE ON CUTTING FORCE AND GENERATED TEMPERATURE IN AN ORTHOGONAL TRUNING PROCESS) Second Engineering Scientific Conference College of Engineering University of Diyala16-17, (2015) pp. 706-712.

[18] Ye Li, a, Chunbin Cai (Finite Element Analysis of High Temperature Alloy Cutting Process Based on Abaqus) Key Engineering Materials Vol. 667 -(2016), pp. 237-243.

[19] Suha K. Shihab, Zahid A. Khan, Aas Mohammad, Arshad Noor Siddiquee (Effect of Cutting Parameters on Cutting Forces and MRR During Turning Hard Alloy Steel with and Without Coolant) International Journal of Engineering and Advanced Technology (IJEAT) Volume-3, (2013) Issue-1.

[20] Changfeng Yao, Zheng Zhou, Jiyin Zhang, Daoxia Wu and Liang Tan (Experimental study on cutting force of face-turning Inconel718 with ceramic tools and carbide tools) Advances in Mechanical Engineering, Vol. 9(7) (2017) pp.1-9.

[21] G Venkatesh - D Chakradhar (Influence of Thermally Assisted Machining Parameters on the Machinability of Inconel 718 Superalloy) Springer Science+Business Media DordrechtDOI 
3D FE- Simulation of Thermally Assisted Turning of Inconel-718 for Cutting Forces Prediction

[22] Ta ric, M., Kovac, P., Nedic, B., Rodic, D., Jesic, D (TOOL WEAR, CUTTING TEMPERATURE AND CUTTING FORCE DURING TURNING HARD STEEL) doi.org/10.24867/(2017)JPE--02-013.

[23] SEIN LEUNG SOO (3D MODELLING WHEN mGH SPEED END MILLING INCONEL 718 SUPERALLOY) unpublished Doctor of Philosophy Thesis Submitted to, (2003) pp.10-80, The University of Birmingham.UK

[24] T.ozel. I.Lianos.J.Soiano and P.J.Arrazola (3D FINITE ELEMENT MODELLING OFCHIP FORMATION MACHINING INCONEL 718: COMPARISION OF FE SOFTWARE PREDICTION). Machining science and technology 15: (2011) pp. 21-46.

[25] P.DEEPAGANESH (FINITE ELEMENTSIMULATION IN ORTHOGONAL MACHINING OF INCONEL 718 ALLOY),International Journal of Mechanical Engineering and Research, ISSN 0973-4562 Vol. 5(2015)pp.49-52 No.1. 